\title{
¿SOY NIÑA O NIÑO? ROLES DE GÉNERO EN LA PREESCOLARIDAD. ESTUDIO DE CASO CHILENO.
}

\section{AM I A GIRL OR A BOY? GENDER ROLES IN PRESCHOOL. CHILEAN CASE STUDY.}

Resumen: La descripción de los roles de género en la pre-escolaridad chilena podría permitir la visibilización de la identidad en la comunidad escolar y familiar. Este estudio de caso particular, poco común en las ciencias sociales, da cuenta de un proceso inicial de construcción de la identidad de género y de una mirada estereotipada de las y los adultos. Niñas y niños, apropian conductas del mundo, pero también las transforman en características que potencian sus personalidades. A pesar de la importancia educacional y personal que tiene reconocer nuestra identidad de género, la normalización de los roles sólo permite la estereotipación de conductas inamovibles, olvidando que lo femenino y masculino no son un dualismo.

Palabras Claves: Roles de género, Pre-escolaridad, Estereotipos de género, Chile.

Abstract: The description of gender roles in Chilean pre-schooling could allow the visibility of identity in the school and family community. This case study, unusual in the social sciences, accounts for an initial process of constructing gender identity and a stereotyped view of adults. Girls and boys, they appropriate behaviours of the world, but also transform them into characteristics that enhance their personalities. Despite the personal and educational importance of recognizing our gender identity, the normalization of roles, only allows the stereotyping of immovable behaviours, forgetting that the feminine and masculine are not a dualism.

Key Words: Gender roles, Preschool, Gender stereotypes, Chile. 


\section{INTRODUCCIÓN}

Este artículo abarca los resultados de un estudio etnográfico realizado en un Jardín Infantil chileno de la Junta Nacional de Jardines Infantiles (JUNJI). La importancia de esta investigación radica en la visibilización de la temática de género en el ámbito escolar, abriendo una puerta hacia la equidad de género desde edades tempranas, una arista social y cultural que se encuentra escondida bajo los mantos de lo cotidiano, olvidando su importancia a la hora de prevenir el ejercicio de la violencia en contra de los géneros, por esta consideración, se insiste en la creación de un programa educador, y reeducador, que incluya a las diferencias sexuales, entendiendo que no se trata sólo de categorías fijas del femenino y el masculino.

La importancia de visibilizar las conductas de niñas y niños en torno al género contribuyó a una caracterización de sus roles que, si bien, corresponden en cierta medida con el imaginario sexista de las adultas, también se pudieron observar distinciones en sus habilidades genéricas, por ejemplo, los niños tienen mayor consciencia de perfección en sus trabajos manuales y creación de coreografías y las niñas, tienen una alta despreocupación por las manualidades, además de un desinterés por lo que se considera materno.

Como consideraciones teóricas, se incorporó a Judith Butler (2006) y su artículo acerca de las regulaciones del género; Marta Lamas (2002) y sus artículos acerca del sexo y el género; Pierre Bourdieu (2002) y sus aportes en dominación masculina y violencia simbólica; y, por último, en construcción de femineidad y masculinidad, Marcela Lagarde $(1989,1993,1996)$ y Michael Kimmel (1997), respectivamente.

En términos metodológicos se utilizó como pieza fundamental el Diseño Flexible que recomienda Mendizábal (2006), debido a lo exploratorio de la investigación, además de permitir el diálogo entre la estructura, objetivos, metodología, teoría, y la recolección de datos, permitiendo adaptar las técnicas y favoreciendo la elasticidad de la información.

El género como objeto de estudio en las ciencias sociales es aparentemente reciente, y lo es aún más el estudio de género en niños y niñas, pues pareciera ser que la literatura ha olvidado que los y las infantes también son actores que copian, producen y reproducen conductas que en un futuro temprano ayudarán a moldear sus propias identidades, conformando un estilo de sociedad. Tanto en los pocos estudios sociales en torno al género, como en la percepción general de la comunidad científica y popular, se responsabiliza a la socialización y a la influencia del mundo adulto, de las costumbres y estilos de las niñas y niños, por lo que nadie se ha preocupado, como fuente principal, de observar el mundo de la niñez.

Con esta caracterización de los roles de género encontrados se pretendió brindar información acerca de una temática poco hablada al interior del sistema educacional, ayudando a facilitar el modo en que se abordan las temáticas de género dentro del establecimiento preescolar y futuramente en las familias de cada menor. 
Por último, vale comentar que lo que se muestra a continuación no pretende actuar como ley general, se reitera que se trata de un estudio de caso particular, sin embargo, podría tratarse de datos importantes a la hora de pensar en un estilo de educación inclusivo. Cada conjetura y cada interpretación que se muestra en esta investigación debe ser estudiada con mayor detalle y aplicada en un número mayor de jardines infantiles, tanto a nivel comunal, como regional y nacional.

\section{OBJETIVOS}

General: Analizar la construcción de la identidad de género de niñas y niños preescolares que pertenecen a un Jardín Infantil y Sala Cuna JUNJI, de la ciudad de Valdivia.

\section{Específicos}

Describir el rol del cuerpo, de niñas y niños, en la construcción de su identidad de género.

Describir las relaciones entre los sexos (niñas-niñas / niños-niños) e intersexo (niñas-niños / niños-niñas), ya sea de afecto, poder, sumisión, y otros relacionados con la construcción de género.

Identificar la trasgresión, de niñas y niños, a las normas y pautas sociales que estén asociadas al género.

\section{METODOLOGÍA}

Esta investigación contó con una metodología cualitativa de diseño flexible. Se trabajó a través del estudio etnográfico, con técnicas de observación y conversaciones intencionadas y no intencionadas, con entrevistas semiestructuradas sólo a adultos y adultas como apoderadas y profesionales del área educativa.

El diseño flexible que propone Mendizábal (2006) se refiere a una propuesta que incluye la posibilidad de adaptación del diseño a la realidad observada en el campo durante la investigación, en este caso la flexibilidad se mostró en las técnicas de investigación y la orientación final que llevó a los resultados.

Unidad de Estudio: La muestra contempló como sujetos de estudio a niños y niñas del Jardín y Sala Cuna " $X$ " perteneciente a la Junta Nacional de Jardines Infantiles (JUNJI) de la ciudad de Valdivia, Chile. Otros sujetos que participaron directa o indirectamente fueron apoderados y apoderadas, educadoras y asistentes del establecimiento, además de la Directora, quienes ayudaron a contextualizar el estudio.

"Because of the delicate nature of this type of fieldwork, most researchers avoid it altogether. However, to grasp what is important in children's lives and to study children 
as children, it is important to frame children as the primary informants of their lives, thus positioning them not as passive subadults but as active participants in society" (Thomas, 2006, p. 44)

Los niveles participantes en la observación fueron: Sala Cuna Mayor, Nivel Medio Menor y Nivel Medio Mayor.

Técnicas de Recolección de Información: En el estudio de la antropología de la niñez no existen técnicas que confirmen efectividad a la hora de trabajar con niñas y niños de cualquier edad. García y Hecht (2009) creen que como en toda investigación antropológica la observación participante es la más considerada y adecuada, sin embargo, consideran que se pueden utilizar otros medios, como:

"entrevistas (charlas coloquiales, pedido de información específica), uso de dibujos (tanto como un fin en sí mismo como un medio para luego trabajarlo en la entrevista), juegos, el pedido a los niños de textos escritos específicos y el trabajo con medios audiovisuales" (2009, p. 171)

Para efectos de esta investigación se optó por utilizar la observación al interior de la institución escolar, vale decir, durante sus actividades educativas y recreativas. Esta técnica de recolección de datos como definen Taylor y Bodgan (1992) involucra la interacción social entre el investigador y sus informantes recogiendo datos sistemáticos. Aquí el diseño flexible fue esencial ya que mientras no se entra al campo se desconocen las preguntas y su planteamiento, por lo tanto, aprender del terreno sin hipótesis preconcebidas ayudó en el proceso de extrañamiento.

La observación se llevó a cabo en aulas, hall y patio del Jardín Infantil, en contacto continuo con el mundo de la niñez, vale decir, juegos, juguetes, conversaciones, caídas, llantos y alegrías. Durante estas instancias, entonces, surgieron diálogos espontáneos entre niños y niñas en las cuales la investigadora pudo inmiscuirse, pero además existieron conversaciones intencionadas que estuvieron pautadas para ser utilizadas en contextos no formales con niñas y niños, las que tuvieron menor éxito.

Las entrevistas semiestructuradas no se consideraron parte del estudio etnográfico por su poca efectividad en el mundo de la niñez, por esta razón se utilizaron las conversaciones intencionadas y no intencionadas, para recolectar información. Las conversaciones guiadas no intencionadas fueron aquellas en que la investigadora se sumó a conversaciones ya iniciadas por niñas y niños, y éstas fueron guiadas hacia temáticas del interés del estudio. Por otro lado, las conversaciones intencionadas se refieren a aquellas instancias en que la investigadora propuso los temas. Este estilo tuvo menor éxito, puesto que tanto niñas como niños no responden con la lógica adulta, obteniéndose mínimos resultados.

Finalmente, utilizar herramientas del estudio etnográfico, permitió relacionarse con niños y niñas en su propio espacio y también bajo sus condiciones, por ejemplo, dejándome entrar en sus juegos, haciéndome partícipe de sus conversaciones e incluso respondiendo mis preguntas. 
"Ethnographic research offers an opportunity to understand how children are defined in specific cultural contexts, which enables the research of children as children, instead of as small adults or passive, inactive members of society" (Thomas, 2006, p. 41)

Análisis de la Información: El análisis de datos estuvo regido por matrices de información confeccionadas a partir de los objetivos del estudio, de esta manera la investigación se guio por una pauta de observación y conversación. A esta se le suma una pauta que alberga dimensiones transgresoras al género estereotipado, la que se construye durante el proceso de investigación, aspectos que Alberti (1999) describe en su texto para comprender cómo la identidad de género de niñas-niños se construye tomando aspectos de su entorno, pero también transgrediendo a ese mismo medio.

Para ayudar con el proceso de triangulación de información se consideraron entrevistas semiestructuradas a 15 adultos significativos, 10 apoderadas y 4 profesionales de la educación y la Directora del establecimiento, además de la revisión de las fichas de registro de cada infante, rescatando antecedentes socioeconómicos y construyendo un contexto, a partir de los aspectos socioculturales de las familias.

\section{MARCO TEÓRICO}

Se cree que la temática más invisibilizada en el estudio de las ciencias sociales es el género, en todos sus ámbitos, sin embargo, más ignorado ha sido el mundo de la niñez y su construcción del género en edades tempranas. Popularmente se cree que niñas y niños no poseen orientación del deseo y por lo tanto su asignación de género actúa sólo como diferenciador entre quienes son femeninas y quienes son masculinos, bajo este aspecto entonces, las y los adultos han transmitido culturalmente ciertos patrones de conducta que cumplen con un canon distintivo para mujeres y hombres como opuestos, creando un imaginario de un correcto comportamiento femenino o masculino. Por esta razón es importante considerar que niñas y niños no son actores pasivos como lo cree el adultocentrismo, y, por lo tanto, deciden e inciden en las opciones de su propia vida.

Si existiera un sistema de educación que potenciara las igualdades sexuales y de género, bajarían los niveles de violencia hacia la mujer y el estereotipo maltratador de los hombres, valorando la libertad de expresión y no un correcto comportamiento de acuerdo con el canon, puesto que las niñas también desarrollan conductas violentas y los niños también poseen un lado sensible y oprimido. Lo que se presenta a continuación son tres perspectivas que este estudio roza a partir del estudio de género. Con este detalle se pretende introducir la mirada antropológica para desarrollar los datos obtenidos en terreno.

Se debe considerar, que se trata de un estudio de caso etnográfico, por lo tanto, no se desprenden leyes generales. Sin embargo, existen ciertas similitudes entre esta investigación y una práctica profesional realizada en 2013, las que están ligadas a la capacidad accionaria y 
transformadora de la niñez y la temprana construcción de una identidad de género que no sólo se vincula al proceso de socialización sino, también a las elecciones y rechazos que rozan a la norma. Se destaca, por último, que entre más temprana es la observación, menos estereotipada es la adopción del género.

\subsection{Antropología y Niñez}

Los primeros sujetos válidos de investigación en la antropología fueron hombres, poco a poco y muy recientemente las mujeres han logrado ocupar el papel de sujetos visibles como foco de atención de las ciencias sociales, pero niños y niñas no han constituido en sí mismos un sujeto de estudio para la antropología.

De acuerdo con varios autores, como Pachón (2009), Vergara (2008), Colángelo (2003), otras y otros, el mundo de la niñez ha sido un objeto y sujeto relativamente nuevo de estudio. El recelo al estudio con niños y niñas ha recaído incluso en la comparación del infante con un ser menos civilizado, con necesidades de crianza y en vías de convertirse en un ser racional (Rausky, 2010). Sin embargo, los estudios recientes que han considerado al niño y la niña como sujetos de investigación, alrededor de los 7 años en adelante, han visto en ellos y ellas una mirada distinta de los fenómenos del mundo de los cuales también son partícipes, pero además se han dado cuenta que esos niños y niñas son en realidad actores del mundo con capacidad de accionar sobre el curso de su sociedad.

Si aún, los antropólogos y antropólogas no han incursionado en edades más tempranas, es decir, antes de los 7 años, podría explicarse a través del tabú contra la credibilidad de niños y niñas, pues se cree que entre más temprana es la edad, la niñez es más irracional y sabe menos del mundo en el que vive. Pero esta negativa sólo ha limitado que niños y niñas sean los protagonistas de sus propias historias.

Durante mucho tiempo, y en corrientes como Cultura y Personalidad, niñas y niños fueron tomados para explicar ligeramente cuál era el proceso que las personas recorrían para convertirse en adultos, también fue considerado por esta corriente el modo en que la adultez influye en la niñez. Otros enfoques evolucionistas como el de Kidd (cit. en Pachón 2009) consideraban que el estado adulto no se veía completo hasta que no se conocieran los inicios de la vida. También esposas de antropólogos en el campo se dedicaron a estudiar a mujeres y niños de las tribus o sociedades recónditas, pero difícilmente se ha encontrado en la literatura, trabajos sistemáticos o exclusivos que tomen a la infancia como objeto válido de investigación (Pachón, 2009). Sin embargo, la fascinación por centrarse en el adulto como sujeto más válido de investigación no sólo actúa sobre la niñez, también lo ha hecho sobre la juventud y la edad adulta mayor.

Duarte (2012) describe a este adultocentrismo como la matriz que sitúa a lo adulto como punto de referencia "en función del deber ser, de lo que debe hacerse para ser considerado en la 
sociedad (madurez, responsabilidad, integración al mercado de consumo y de producción, reproducción de la familia, participación cívica, etc.)" (2012, p. 64)

Siguiendo la línea de Duarte (2012) la sociedad adulta ve en la socialización la obligación de imponer los roles que le permitan a las futuras generaciones desenvolverse de manera correcta, este tipo de carga normativa y moral se reproduce a través del tiempo y cuando la generación de niños y niñas se vuelve adulta cree también necesaria la transmisión de las prácticas que ellas y ellos recibieron en su infancia.

La socialización, por otra parte, ha sido la eterna responsable de la transmisión social y cultural. Se ha desenvuelto como clave en la crianza y no ha dejado cabida a la decisión del niño o la niña a convertirse en lo que desea. Si bien, se debe reconocer la potente capacidad moldeadora de la socialización a través de la transmisión de pautas y normas, no se debe olvidar el derecho a decidir ni la posición de acción de los sujetos, sean estos niños o adultos.

Entonces, de lo que se han olvidado la socialización y el adultocentrismo es que las y los niños son actores sociales capaces de comprender, reproducir y producir historia, se trata de personas con cabida accionaria y reaccionaria a su contexto, y por lo tanto no son puramente sujetos pasivos.

Nunes (1999), en esta línea, propone una antropología del niño "interesada en interpretar el modo en que los niños entienden el mundo y su sociedad" (en Colángelo, 2003, p. 5). De aquí se desprende este estudio, una búsqueda que se sumerge en la niñez y que pretende rescatar sus nociones género en una construcción temprana de su identidad. Porque:

"Marcados como puros y pasivos por esencia, se otorga a los niños el derecho a la protección, pero, al mismo tiempo, se les niega la capacidad de actuar y la autonomía. Incapaces de entender la infancia como una interpretación histórica, social y política, entremezclada con las relaciones de poder, muchos adultos envuelven a los niños en un aura de inocencia y proteccionismo" (Giroux, 200, p. 14)

La niñez es una etapa etaria que permite transformar el mundo en el cual se desenvuelve, su posición accionaria absorbe los sentidos de su cultura y los recrea posibilitando un cambio progresivo. Las y los niños de hoy no son como las y los de ayer, ni tampoco serán como las y los del futuro.

Reybet (2009), aporta algo interesante diciendo “...el niño no sabe menos, sabe otra cosa. Para la antropología la cuestión no pasa por saber en qué condición cognitiva elabora sentidos y significados, sino a partir de qué sistema simbólico lo hace" $(2009$, p. 6) Así, a la antropología no debiera importarle el nivel evolutivo del niño o la niña sino su capacidad para captar y dotar de sentido al mundo que le rodea, pues poco a poco reconoce y se apropia de éste. Realizar estudios en las etapas de infancia supone conocer una parte de la vida que no ha sido explorada y que desconocemos como adultos, las y los niños participan de la sociedad a la que pertenecen y es 
por eso que su estudio es importante, no porque sean mini adultos, sino porque son parte de la cultura, viviéndola y transformándola.

La antropología de la niñez, como corriente ha comenzado a legitimar al niño y la niña como sujetos de investigación, haciéndoles participar en sus técnicas de recolección de datos, siendo los entrevistados y los protagonistas, sin embargo, las edades de estos actores se han concentrado, en promedio, desde los siete años en adelante. En este sentido se sigue ignorando una parte de la infancia, la más temprana. Debido a ello es que esta investigación pretende tomar los temas invisibilizados para mostrar una parte del mundo ignorado que posee potentes datos de conocimiento.

Olvidar a la infancia provoca seguir reproduciendo una idea de la niñez que cada vez menos tiene que ver con la realidad observable. Y por lo tanto las políticas públicas siguen enfocándose en una niñez que día a día desaparece.

“...la elaboración y el diseño de iniciativas promotoras de su participación, en su mayoría, son hechas por personas adultas, sin considerar las opiniones o intereses de la población infantil. Esto trae consigo al menos dos problemas: al no atender a las necesidades e intereses de niños y niñas, no se capta su atención, por tanto, no concitan su participación ni asistencia. Y, por otro lado, a nuestro parecer el aspecto central y de mayor importancia, esta situación contribuye a reproducir representaciones sociales sobre la infancia, reproduciéndose prácticas participativas normativizadas y validadas por la institución, privándoles de una participación genuina" (Lay, 2012, p. 10)

Es posible que la antropología, en particular, se aleje del estudio en niños por no existir metodologías que le permitan la recolección de datos. Si bien es cierto es una osadía el trabajo con niños, es posible su ejecución, ya sea adaptando las técnicas o creándolas, en especial la observación participante cuenta con un beneficio inexplorado por la ciencia en esta etapa de la vida. La búsqueda por el conocimiento del ser humano requiere de una profundización en las edades tempranas, ya que la identidad no es constante ni inamovible, la identidad es histórica, es etaria y es cambiante.

\subsection{Antropología y Género}

El género, en este análisis no supone una dicotomía femenina o masculina, ni tampoco se encasilla de acuerdo con el sexo o sus genitales. Se entiende al género como la condición libre de comportarse dentro la norma o fuera de ella, reconociendo que no sólo se trata de uno, dos, tres o cuatro géneros, sino que las posibilidades son ilimitadas. Respetando su sentir y la apropiación de su condición genérica es que se crea la identidad. Nicholson (1989) no entiende al género como natural y dado, sino construido, por lo tanto, es importante reconocer la significación social y cultural que se le atribuye más que banalizar al término.

Cada cultura y sociedad alberga diferentes identidades, ya sean estas colectivas o individuales, cada regla de comportamiento se impone e interpreta de acuerdo con las 
motivaciones e intereses del grupo posibilitando la transformación de estas en el tiempo y el espacio. Lara (1991) propone que desde el punto de vista antropológico la identidad no se considere fija ni inmutable, más bien se trataría de un nosotros que nace por oposición a un otros que se mueve para alcanzar o transformar sus reglas.

Así mismo, la identidad de género también responde a un proceso social de cómo me veo y cómo me ven los demás, y que según Lara (1991) se liga a las prácticas sociales, éstas pueden adaptarse a diversos contextos, así como integrar o desechar conductas y gustos. Las identidades, y la de género específicamente, se aprenden por varios medios, la socialización, la imitación, la admiración, la cotidianeidad y otros, que influyen en nuestra opción de pertenencia a cierto grupo, pero no necesariamente la construyen en su totalidad.

Como cada grupo quiere diferenciarse, los niños también se apartan de las niñas, pues no se vive de la misma manera la vida como niño que como niña, en este aspecto Colángelo destaca que "Innumerables avatares por los que transita la niña son propios de su género y hablan de otras historias de la historia" (2003, p. 4). Así se puede apreciar que la infancia es más que una apreciación unisex, pero en la crianza se produce un límite estereotipado entre los roles del niño y la niña.

"fomento para los hombres y el impedimento para las mujeres de una serie de aptitudes, intereses, valores y rasgos de personalidad, y viceversa; así como en la difusión, a través de las instituciones sociales, de los dos conjuntos de rasgos estereotipados, masculino y femenino, de tal manera que los niños y niñas vayan aprendiendo los rasgos que se consideran propios de su sexo" (Moya, 1984, p. 2)

Desde la antropología, en este estudio, el interés por la identidad de género de preescolares radica en su deseo por visibilizar prácticas que por años han sido mantenidas bajo la socialización y el estereotipo. Niñas y niños también son sujetos de estudio que construyen identidad, no sólo se dedican a seguir pautas, también las transforman, y es esta interacción la que finalmente devela un proceso social.

La identidad de género, construida gracias a varios elementos, se legitima a través del propio sentir y la manera en que aquello encaja en la sociedad en que se vive, para esto las y los individuos se adaptan a roles de género que indican el correcto comportamiento para hombres y para mujeres, dando orden a los sexos biológicos en el área social. Estos roles se han encasillado con el tiempo, a pesar de las transformaciones en el hogar, en el mundo laboral y emocional, la memoria colectiva sigue recordando a los roles de género como exclusivos, es decir, lo que hacen hombres no deben hacer las mujeres ni viceversa, perpetuando la dominación masculina a través del tiempo y los espacios.

Aunque la antropología feminista y otras corrientes han estado preocupadas por el estudio que reconozca las diferencias sexuales y de género, de este y otros tiempos, se han olvidado de otras edades que no sean las adultas, es por ello la pertinencia de este estudio, pues la configuración del género está presente desde antes que el niño o la niña nazca y es 
transformada por ellos en el transcurso de su vida. En este sentido, el género toma fuerza "en la medida en que los procesos de significación elaborados en la simbolización cultural de la diferencia sexual producen efectos en el imaginario de las personas." (Chacón, Pons y Cabrera 2011 , p. 5), desde aquí se arman las identidades, llevando consigo la normalidad con la que encaja un sexo, un rol y una identidad.

Pero en la diversidad cultural y social no existe ni un solo sexo, ni un solo rol, ni una sola identidad, en la realidad se mezclan cada uno de ellos para formar un yo y un otro que se siente libre con su condición, por lo tanto, el encasillamiento normal, casi obligatorio, está restringiendo la libertad de ser quien se es. La identidad de género no es fija y probablemente tampoco sea coherente como dice Rodríguez (2006), por lo tanto, ya es hora de que se reconozca la verdadera complejidad del género y el sexo, y las diferentes formas en que un hombre se transforma en hombre o en mujer, y una mujer se transforma en mujer u hombre.

Niñas y niños viven el estereotipo de género, pero también tienen su propio estilo de creación de identidad. Si bien la feminidad se aprende con el tiempo y se interioriza con los años y la masculinidad se perpetúa a través de los beneficios que trae consigo ser hombre, existen aspectos ignorados por los adultos y adultas que favorecen la normalidad e invisibilizan la diferencia.

Cada cuerpo biológico posee características propias que ayudan a construir personalidad e identidad, pero a pesar de las características particulares de cada cuerpo la sociedad normalizadora utiliza al cuerpo para dictar pautas de normalidad. Por ejemplo, el cuerpo femenino posee rasgos finos y su bandera es la vagina y el cuerpo masculino posee rasgos duros, cuya bandera es un pene; de este modo se clasifica cada ser de acuerdo a su cuerpo y éste debe encajar finalmente con las características sociales y culturales que se indiquen. Pero el cuerpo no es una constante, ha cambiado con el tiempo y lo seguirá haciendo, es una construcción social y por lo tanto responde a la historia.

Entonces, no existe tal naturalidad del cuerpo femenino ni masculino, los significados que se les atribuyen son construcciones históricas y culturales como Lamas (2000) recalca, así el cuerpo se vuelve un instrumento, como una bandera que representa y a la que se le dota sentido. El cuerpo es capaz de sentir lo biológico, de enfermarse y morir, pero también interpreta dolores y placeres, funciona como molde de ejemplo para la regulación y reacciona frente a las normas, ya sea aceptándolas o transgrediéndolas, como dice Lamas (2000) finalmente todo lo social es vivido por el cuerpo.

El cuerpo infantil, también dotado de sentido, debe ser explorado por el propio sujeto infante y a la vez que descubre su cuerpo biológico también conoce su cuerpo socialmente significado, al que interpreta, acepta o rechaza, al que moldea a su propio gusto o al gusto de su sociedad. Entre los 3 años y los 7 años (Chacón, Pons y Cabrera, 2011) los niños y niñas reconocen su cuerpo y se encasillan a sí mismos y los demás de acuerdo con el género, la clase y la etnia básicamente. Espinoza (2007) cree que esta auto asignación comienza entre los 2 años y medio y 
los 3 años, y para ello se valen del cuerpo de los otros y el propio, y los elementos femeninos y masculinos, como la actitud y la ropa.

Las diferencias anatómicas ayudan a construir significaciones culturales y psíquicas sobre el género y la pertenencia de los cuerpos, este terreno aparentemente simple, pues cada cuerpo pertenece a una categoría femenina o una masculina, se complejiza cuando los símbolos no encajan con la norma. Estas normas están tan arraigadas en el subconsciente del adulto y también del niño que se ocultan en el cotidiano, de este modo cuando le preguntas a un niño cómo sabe que es un niño, de inmediato reacciona y se excusa tras la diferencia anatómica. Desde muy temprano es posible apreciar que esta reacción con respecto a las diferencias sexuales y de género se alojan en el subconsciente haciendo compleja la libertad de reconocerse.

Este tipo de regulación hace imposible la aceptación de los cuerpos femeninos y masculinos que no se encuentran bajo categorías normalmente visibles, llevando al mundo de la niñez a cotidianizar un proceso que a todas luces debiera ser hablado y escuchado, pues conocer tu cuerpo es encontrar tu camino. Las significaciones personales quedan hoy, fuera de la norma.

Finalmente, el género hace una integración de la praxis del femenino y masculino, a través del cuerpo como un conjunto biológico y cultural, que se mantiene en la norma y sale de ella. Es necesario también recalcar que el concepto de género se muestra mediante la identidad de género y se normaliza de acuerdo al encasillamiento de sus roles, femenino o masculino.

\subsection{Antropología y Educación}

La educación preescolar en Chile se extiende entre los 84 días y los 6 años, anterior a la fase primaria de escolaridad. Las necesidades de esta etapa pueden estar cubiertas por distintos organismos, como por ejemplo la Junta Nacional de Jardines Infantiles (JUNJI), la Fundación Integra y otros privados, quienes brindan educación, cuidado y contribuyen a la igualdad de oportunidades de niñas y niños.

En el caso de este estudio, las observaciones se llevaron a cabo al interior de un Jardín Infantil y Sala Cuna de la ciudad de Valdivia (Chile) perteneciente a la Junta Nacional de Jardines Infantiles (JUNJI). La JUNJI es una institución escolar del Estado creada en 1970, que trabaja de manera autónoma, pero está vinculada al Ministerio de Educación. Está enfocada principalmente a entregar educación a niñas y niños menores de 4 años, y preferente con vulnerabilidad social.

La escuela tanto como la familia, y la iglesia, han sido los agentes socializadores y normalizadores por excelencia en nuestra sociedad. Si bien, en nuestros días las Iglesias diversificaron su poder, éste aún puede ser visible, sin embargo, la Escuela y la Familia siguen funcionando, cada uno a su manera a través del tiempo, como moldeadores y formadores, convirtiendo a niños en adultos responsables que encajen con su respectiva sociedad.

Este sistema escolar y familiar transmite las herramientas necesarias para que el o la infante se desenvuelva con éxito en un futuro temprano y lejano. Este tipo de educación 
normalizador y regulado solo contempla posiciones de orden, por lo tanto, las capacidades de aprendizaje parecieran solo moldear al individuo

Cada niño y niña tiene un círculo cercano del cual absorbe información, ya sea imitando, caricaturizando o recreando, este proceso de socialización funciona como una influencia de un grupo dominante que ayuda a construir las reglas y formas de relacionarse con los otros y otras mediante un proceso de convivencia o imitación de pautas y actitudes, en este caso, el grupo dominante del que se habla es el mundo de la adultez.

Esta ayuda no es siempre consciente por parte de las y los adultos, de hecho, Splinder (1993) expone que las "personas pueden transmitir cultura sin saber que lo hacen...es probable que la mayor parte de la cultura se transmita de esta forma más que con una intención consciente" (1993, p. 209) De este modo, las pautas aprendidas por los adultos son tan fuertes que las transmiten incluso sin darse cuenta, dificultando la liberación de viejos cánones como la dominación. Sin embargo, volverse consciente de nuestra inconsciencia podría resultar el primer paso para enseñar, tanto en la Familia, como en la Escuela.

A parte de la socialización como tal y como efecto de los adultos, los niños y niñas utilizan los juegos como recreación de lo que ven y sienten, es su momento de manifestarse, burlarse, caricaturizar y transformar las pautas que las y los adultos han transmitido.

Thomas (2006), muy bien agrega que el juego suele ignorarse porque se cree que es una simple imitación, por lo tanto, los psicólogos y antropólogos solían teorizar el juego como una conducta en que los niños y niñas practican ser adultos, sin embargo, el juego es más que la imitación, es más bien la transgresión y a veces también aceptación de un mundo que están aprendiendo a conocer.

"One way to construct play more broadly is to see it as a mechanism through which children gain knowledge and understanding of their environment. Their environment includes adults, and often children did imitate adults in their lives. But their worlds are much more than the adults who teach them" (Thomas, 2006, p. 48)

Cuando la socialización, en la educación lleva consigo las aristas de dominación y violencia, es cuando las Ciencias Sociales aparecen para decir que hay procesos sociales en los cuales la violencia simbólica se hace evidente por diferentes razones de acuerdo con la sociedad o cultura en cuestión.

La búsqueda de estas razones en el caso del género es lo que intenta captar esta tesis en el ámbito educacional. Muy frecuentemente el curriculum escolar, y sobre todo el curriculum oculto, olvidan enseñar una perspectiva de género que ayude a sus estudiantes a consolidar una identidad que le sea fiel a su sentir. Las normas de género están tan interiorizadas que replican las pautas masculinas para niños y femeninas para niñas. 
Por un lado, programar actividades separadas para cada género supone roles distintos, dificultando la participación mixta. Por otro, la intencionalidad de las educadoras, condicionada por su crianza y las relaciones de poder en la que viven complejizan el avance a una educación inclusiva.

El rol de la antropología en este aspecto podría ser fundamental al visibilizar prácticas cotidianas que se desenvuelven en el mundo escolar. Se trata de visibilizar el curriculum oculto y hacer partícipe a los protagonistas, a través del estudio que muestra las potencialidades de construcción entre niños y niñas. En este ámbito la coeducación aparece como modelo esperanzador en tanto propone un estilo educativo que integra tanto al niño y niña, como a los adultos. Este tipo de métodos abriría la ventana hacia un mundo infantil presente.

\section{DESCUBRIENDO UN MUNDO INVISIBLE}

Respondiendo al objetivo general planteado en este estudio, describir los roles de género que niños y niñas preescolares manifiestan en su sitio escolar, se presentan los resultados trabajados en torno al proceso de interpretación y reflexión para obtener la caracterización de roles de género de niñas y niños en edades tempranas.

Durante el proceso preescolar, niñas y niños se preocupan de sus sistemas de relaciones, tanto con pares como con referentes mayores, además son capaces de captar, aprender y reproducir reglas ligadas al comportamiento positivo o negativo, la higiene y el cuerpo, experimentan también, diversas emociones y reconocen con qué actitudes o actos son capaces de llamar la atención (San Pelayo, 2008), por lo tanto, se entiende que el proceso de edad temprana es fundamental a la hora de observar la construcción de los roles de género, pues se trata de la edad en que experimentan el mundo desde diferentes ámbitos, de manera que crean y recrean sus estilos de vida.

De acuerdo con la Colección "Currículo I" del Marco Curricular de la JUNJI, publicado en 2005, existen temas transversales a aplicar, éstos corresponden a "estilos de vida saludable, análisis diferencial de género y afectividad" $(2005$, p. 8). Con respecto a la perspectiva de género se considera su integración en la "forma equitativa tanto de la figura masculina como la femenina" (2005, p. 15) posibilitando la elección de "los niños más allá de los roles establecidos tradicionalmente para uno u otro sexo" (2005, p.15). Tomando en cuenta que, a niveles teóricos, e institucionales, el enfoque de género se encuentra reconocido, estos planteamientos transversales no bajan a las bases comunales o regionales de todo el país. Si bien es cierto existe financiamiento para la capacitación del personal en torno a diferentes temáticas, incluyendo el género, la demanda de recursos para cubrir otros aspectos, también importantes, impiden la gestión específica de invertir en estudios de género. De este modo se comprende el desconocimiento de las educadoras, asistentes y apoderadas/os acerca de la temática del género y las prácticas sexistas reproducidas tanto al interior de sus casas como en el espacio escolar. 
Es posible que la invisibilización del género esté formada por dos procesos, conjuntos o separados. El primero correspondería a las prácticas de crianza de las y los adultos que reproducen contextos patriarcales, impidiendo descotidianizar sus vivencias. Y el segundo, que, a pesar de la inserción femenina al mundo laboral, las mujeres siguen ligándose a labores relacionadas con lo doméstico (Maldonado, 2003), de este modo en vez de existir un proceso de inclusión del femenino, como emancipatorio, sigue normándose y encasillándose, incluso desde sus propios discursos.

Del contexto familiar se rescata, que a pesar de la existencia de madres solteras y la inserción laboral de casi el total de las apoderadas, su posición frente al sexo y el género fue difícil de descifrar. Por otro lado, el nivel educacional de las madres o apoderadas de niños y niñas tendió a estudios más completos que el de padres o apoderados. Este hecho, no menor, también debería funcionar como emancipador de los roles femeninos, sin embargo, no posee ningún valor a la hora considerar a las mujeres en el ejercicio de poder.

De los análisis se desprende, primero, el desconocimiento del concepto de género en el mundo adulto, las apoderadas tienen una definición vaga del término, lo que confirmaría que la visibilización del estudio de género es necesaria para una construcción de la identidad menos juzgada y estereotipada. Segundo, la subordinación femenina, a pesar de tratarse de mujeres que se abrieron paso en el mundo laboral; tercero, la caracterización típica del femenino y masculino, pero también esta visión de la mujer moderna emancipadora, de la cual no se apropian; y cuarto, la reproducción de roles sexistas inconscientes, ya que estas conductas sólo aparecieron cuando se les pidió describir un día normal de actividades.

Otro punto importante, es la influencia en el modo de crianza que ejercen las primeras generaciones que conviven en el hogar, me refiero a abuelos y abuelas, quienes tienen una visión de mundo bastante distinta, de tipo muy patriarcal, lo cual no permitiría una educación integradora del sexo y el género, mismo caso ocurre, por ejemplo, con la alimentación saludable, pues se considera al sobrepeso como una característica positiva de niñas y niños, y así mismo ven en los juegos bruscos un comportamiento normal de niños y en los juegos de té un comportamiento normal para niñas.

\section{CARACTERIZACIÓN DE LOS ROLES DE GÉNERO}

Los roles de género son una construcción sociocultural que funciona como expectativa de del comportamiento femenino y masculino, y según Guzmán ( $S / F)$, estos roles se nutren de diversos elementos, tales como los autoconceptos, las características psicológicas, los roles familiares, las tareas ocupacionales y las referencias políticas.

Las características correspondientes a cada género se vuelven dicotómicas, y, por lo tanto, lo masculino no quiere parecerse a lo femenino (Kimmel, 1997), ni viceversa, en este sentido sus características funcionan como el opuesto. De acuerdo con el conocimiento convencional, estas 
normas deben hacerse valer para lograr la inserción dentro de un conjunto social, de este modo se crea identidad a partir de lo que se es por dentro, pero también, con lo que se quiere compatibilizar por fuera.

En general, los asuntos de género suelen conocerse a través de esta arista dual del concepto, y se crea un constructo tan obvio que se invisibiliza sin cuestionar sus fronteras. Del estudio se desprende que las caracterizaciones que las actoras hacen para los roles de género son un contraste, mientras que las niñas son delicadas, los niños son bruscos, ellas manejan el sentido de la belleza, ellos son desarreglados, sin embargo, la visión estereotipada del género no se refleja completamente en las observaciones, aunque es interesante destacar que las actoras socializadoras inconscientemente se empeñan para que niñas y niños cumplan con sus cánones correspondientes (Tabla 1).

Tabla 1. Percepción de actoras socializadoras contrastado con la observación en aula:

\begin{tabular}{|c|c|c|}
\hline \multirow{4}{*}{ Niñas } & Opinión & Observación en Aula \\
\hline & $\begin{array}{l}\text { "Muy } \\
\text { Mamás" }\end{array}$ & $\begin{array}{l}\text { El sentido de maternidad se ve reflejado en poca parte de la totalidad de } \\
\text { las niñas observadas, corresponde más bien a una práctica de niñas del } \\
\text { Nivel Medio y lo ejercen sobre niños y niñas menores en edad o tamaño, } \\
\text { o bien, sobre niños de su edad, pero en sentido autoritario. }\end{array}$ \\
\hline & $\begin{array}{l}\text { "Coquetas" } \\
\text { "Femeninas } \\
\text { " }\end{array}$ & $\begin{array}{l}\text { La coquetería es una herramienta que ambos sexos manifiestan cuando } \\
\text { requieren de atención, estas expresiones orales y corporales se } \\
\text { convierten en rabietas cuando la coquetería no funciona sobre el mundo } \\
\text { adulto. }\end{array}$ \\
\hline & $\begin{array}{l}\text { "Carácter } \\
\text { Débil" }\end{array}$ & $\begin{array}{l}\text { En el grupo de niñas de cada nivel, existe una o dos líderes que funcionan } \\
\text { como entes positivos y negativos, ellas se imponen por sobre sus pares } \\
\text { femeninas, pero también sobre su símil masculino. Aun así, existen } \\
\text { ocasiones en que estas niñas se ven subordinadas, pero por sus propios } \\
\text { discursos y quehaceres, más que por una dominación masculina. }\end{array}$ \\
\hline \multirow{3}{*}{ Niños } & "Torpes" & $\begin{array}{l}\text { Es verdad que los niños son más descoordinados y no parecen } \\
\text { dimensionar los espacios por los cuales transitan, sin embargo, este } \\
\text { hecho sólo se ve reflejado en la Sala Cuna. }\end{array}$ \\
\hline & $\begin{array}{l}\text { "Actúan sin } \\
\text { Cuidado" }\end{array}$ & $\begin{array}{l}\text { En los juegos, los niños de todos los niveles se desenvuelven sin cuidado } \\
\text { alguno por el otro u otra, corren sin parar y sin miedo a golpear o tirar } \\
\text { algo. Sin embargo, en el plano del trabajo manual o creativo, cuando se } \\
\text { sienten interesados, colocan toda la delicadeza para intentar obtener un } \\
\text { trabajo lo más cercano posible a la perfección. }\end{array}$ \\
\hline & $\begin{array}{l}\text { "Carácter } \\
\text { Fuerte" }\end{array}$ & $\begin{array}{l}\text { Al igual que en las niñas, existen líderes que se comportan como } \\
\text { influyentes positivos y negativos, por otro lado, también hay niños de } \\
\text { carácter pasivo, los cuales suelen ser subordinados, dependiendo de si } \\
\text { éstos hacen caso a sus pares o si deciden ignorarlos. }\end{array}$ \\
\hline
\end{tabular}

Fuente: Elaboración propia 
El cuerpo es el principal instrumento que facilita la identidad de género, demuestra lo que "yo soy" y lo que "quiero conseguir", y en este sentido Lamas (2000) rescata de Mauss que el objeto y medio técnico más normal y natural de un ser humano es el cuerpo y su movimiento. Las niñas de todos los niveles demuestran su interés a través de la corporalidad, en este sentido su construcción de la femineidad es posible apreciarla mediante sus juegos, sus movimientos al recibir órdenes de su agrado o desagrado, su gestualidad al comunicarse frente a sus pares femeninos y masculinos o sus referentes socializadores.

De acuerdo con esta lógica de movimiento, Maldonado (2003) afirma que las mujeres se desenvuelven dentro del ámbito privado y por lo tanto se ocupan de los intercambios invisibles y cotidianos del su contexto. Bajo este precepto, el encasillamiento de la mujer en tareas poco reconocidas provoca, como propone Espinosa, que "ellas no se reconozcan como protagonistas activas del mundo en el que viven y que, por ello, se perpetúen los tradicionales estereotipos de género" (2007, p.4). Esto explica el por qué las niñas que se muestran líderes de sus grupos reaccionen sumisas cuando se trata del ámbito público. Durante las actividades observadas, las niñas de cualquier nivel pocas veces alzaron la voz para dar su opinión, y en las ocasiones que lo hacían, era sólo en voz baja.

Así no sólo se trata de un exclusión demanda por el estatus masculino, sino que también se produce una autoexclusión, de parte de las propias mujeres, de los asuntos públicos, provocando que el estereotipo del femenino siga reproduciéndose en torno a las labores domésticas y maternales, que como dice Bourdieu, si bien son actividades "aparentemente reconocidas y a veces ritualmente celebradas" (2000, p.71), no son más que momentos simbólicos que ayudan al control y la legitimación de la dominación.

Durante el proceso etnográfico de observación, se registró un claro poder de emancipación de parte de las niñas, en cualquiera de los niveles, éstas se muestran fuertes y claras frente a lo que desean obtener, luchan contra niña o niño si es necesario para la obtención de un juguete o atención, y se comportan como adultas a la hora de regañar a sus pares masculinos. Sin embargo, esta posición de liderazgo femenino se ve opacado cuando el contrincante es un varón de carácter autoritario, frente a esta posición ellas ceden el poder sin siquiera quejarse con las educadoras o asistentes.

Otro elemento característico del género femenino corresponde a la coquetería y la estética. Durante el mes de visitas a los diferentes niveles, ni un solo día las niñas dejaron de asistir peinadas, con detalles en accesorios y colores rosa, morado o naranja. La combinación de colores proporciona estilo a cada una de las niñas y las posiciona en cierto estatus de belleza. Constantemente, las más vanidosas, se miran frente al espejo practicando su gestualidad y revisando que tanto su pelo como su ropa se vean en perfecto estado.

Este tipo de característica comienza como una construcción desde la socialización, puesto que madres y apoderadas eligen la ropa al momento de comprar y vestir a sus hijas, entonces, las niñas apropian este estereotipo y lo reproducen. Aquí ayuda Bourdieu y su visión acerca del femenino: 
"Al estar (las mujeres) así socialmente inclinadas a tratarse a sí mismas como objetos estéticos $y$, en consecuencia, a dirigir una atención constante a todo lo que se relaciona con la belleza y con la elegancia del cuerpo, de la ropa y del porte, ellas se encargan con absoluta naturalidad, en la división del trabajo doméstico, de todo lo que se refiere a la estética y, más ampliamente, a la gestión de la imagen pública y de las apariencias sociales de los miembros de la unidad doméstica: de los niños, evidentemente, pero también del esposo" (2000, p.72)

Lo anterior explicaría, por qué el ámbito laboral para las mujeres está estrechamente ligado al orden y la limpieza, en casi todos los casos, pues se cree que estas labores están hechas para ellas, y por lo tanto las mujeres lo asumen como verdad, buscando desenvolverse en estos ámbitos.

Por último, las mujeres con respecto al poder cumplen dos funciones observadas en terreno. La primera se aprecia en el liderazgo de algunas niñas, y la segunda, se liga a su legitimación del poder masculino. Con respecto a este segundo punto Bourdieu nos aporta:

"Las mujeres participan indirectamente de los juegos de poder, puesto que lo hacen por intermedio de los hombres. Mientras ellos están compelidos a jugar directamente en las luchas por el dominio y, por tanto, a pelear entre sí, ellas se convierten en soportes y apoyos imprescindibles - pero subordinados- para las distintas facciones en lucha. De nuevo, como cuerpos para- otros" (2000, p.72)

Esta ayuda que proporciona el cuerpo femenino hacia la reproducción de la dominación se observa en su incapacidad para negarse frente a las peticiones masculinas. Las niñas del nivel medio, sobre todo, quieren sentirse visibilizadas por el mundo de los hombres, y de este modo acceden a realizar acciones que posibilitan los planes masculinos, pero, sólo cuando las mujeres son menor cantidad que los hombres, en cuyo caso contrario ignoran por completo los intereses de sus pares masculinos.

El contraste entre los datos registrados en el diario de campo y la reflexión en torno al marco referencial refleja que los estereotipos femeninos no se corresponden fielmente en la práctica observada, destacando así que las mujeres sí pueden llegar a usar violencia para conseguir sus intereses, y que existen atisbos de dominación y liderazgo que es más reprimida por sí mismas que por sus compañeros masculinos.

El cuerpo femenino, en la práctica, intenta emanciparse y mantener el control tanto de sus acciones como de las situaciones, pero se ve reprimida por la normalización de las prácticas. Los niños de cualquiera de los niveles, no siempre se comportan de acuerdo a acciones violentas o dominadoras, sin embargo, ellas ceden por un bien común o por cuidado a tres cosas. La primera, represalias por parte de los varones que las superan en número o fuerza, la segunda, sospecha a que los niños las ignoren y las aparten aún más de sus asuntos, y la tercera, la reprimenda por el mundo adulto. De este modo, la supresión corresponde más a un proceso de reproducción personal del femenino, que a la dominación practicada por el masculino. 
El egoísmo entre mujeres observada en casos de convivencia es bastante común, impidiendo que exista sororidad en el grupo, una de las explicaciones puede ser que las niñas no se conocían con anterioridad, sin embargo, este hecho no se observó con tanta frecuencia en niños, por lo tanto, concuerdo con el concepto que tiene Lagarde (1989) acerca de la poca solidaridad por parte de las mujeres, la cual sólo existe en ámbitos de obtención de beneficios.

La masculinidad también es un constructo social y cultural del cual no sólo forma parte el conjunto de hombres de una comunidad, sino que de igual manera participan mujeres en su conformación de identidad, en tanto que lo masculino se define como lo que no es femenino y viceversa.

De acuerdo con aquello, Kimmel considera que "la masculinidad se define más por lo que uno no es, que por lo que se es" $(1997$, p.52) puesto que los hombres son hombres en medida que no son mujeres.

En tanto al trabajo y a la dominación, se consideran un ir y venir llenos de transformaciones, y bajo este precepto Bourdieu considera que los límites de las tareas realizadas por los varones tienen ciertos códigos que cambian al tratarse de específica labor:

“...si un varón no posee las cualidades masculinas de dominación se le desprecia, si realiza actividades femeninas se le subvalora y si aumenta la participación de los varones en dichas actividades, se tiende a valorarlas. Al contrario, si la mujer entra a desarrollar actividades masculinas se la desprecia por masculinizarse, así como se devalúan aquellas actividades que, antes masculinas, pasan a ser realizadas de manera generalizada por las mujeres. (2000, p. 71)

Así, entonces, los hombres tienen la posibilidad de insertarse en ciertos rumbos, cuando se tratan de cambios masivos, llevándose consigo el signo de estatus y aplicándolo a la labor antes desvalorada.

La caracterización del rol masculino, en la práctica, no está relacionado en su totalidad con las visiones que las adultas entrevistadas manifestaron acerca de este género. Si bien, algunas se acercan a la realidad, las percepciones suelen tratarse de un estereotipo que ayuda en buena parte a la construcción de la identidad masculina, creando que la sociedad en la que ellos se desenvuelven les exija ciertas pautas de comportamiento.

Los niños del grupo Sala Cuna Mixta, aún no entienden todo el sistema de reglas que conlleva ser varón, pero es posible observar que sí legitiman su masculinidad cuando se encuentran frente a sus pares. Por otro lado, los niños del grupo Sala Cuna Mayor, ya conocen los juegos de poder y los utilizan con bastante manejo, tienen claro también que ejercen control sobre lo femenino puesto que conocen sus destrezas en fuerza. Finalmente, el Nivel Medio, controla su motricidad y por lo tanto sus movimientos corporales son más refinados, permitiéndose el ejercicio de piruetas; en cuanto a sus trabajos manuales, manejan una percepción acerca de la perfección y son mucho más dedicados que las niñas, sin embargo, no se 
les reconoce esta cualidad, si bien se les felicita, el ejercicio de manualidades y el sentido del arte se le otorga al femenino.

A diferencia de las niñas, quienes buscan acercarse a los asuntos masculinos, los niños tienden a alejarse lo máximo posible de lo femenino. Nunca se mostraron verdaderamente interesados por las niñas de sus grupos, es más, sólo en el Nivel Medio los niños utilizaban a las niñas como un contacto entre lo masculino y lo femenino. La mayor parte del tiempo, los niños, de cualquier nivel, jugaban juntos o separados, pero siempre pendientes de que sus pares estuvieran mirando, de este modo la imitación fue fundamental como medio de legitimación masculina. Kimmel (1997) en este aspecto considera que los hombres buscan la aprobación por parte de otros hombres en un proceso Homosocial que funciona como un sello de calidad.

Por otro lado, pero ligándose al "repudio" o "invisibilización" de lo femenino, los niños recriminan y se burlan de las acciones cercanas a las mujeres, como, por ejemplo: ser muy cercano a la madre, en el caso de niños; y ser gruñona, en el caso de las niñas. En el primer caso, se alejan de aquél que denominan mamón y se burlan por su cercanía con el círculo maternal. En el segundo caso, imitan a las niñas cuando éstas hablan en demasía, pero con tono de burla, es decir, realizan una caricaturización de ellas. Estos ejemplos se relacionan bastante bien con un actuar adulto muy común dentro de la identidad masculina y Kimmel (1997) lo denomina Homofobia; este concepto no se refiere al desprecio o antipatía por la orientación homosexual del deseo, sino al miedo a ser poco masculino, escondiendo este temor tras las burlas hacia todo lo que les haga parecer siquiera un ápice de femenino.

Por último, la construcción de un masculino estereotipado ha provocado que los niños muy tempranamente no quieran identificarse con nada femenino. Sin embargo, mientras se construye su identidad por medio de la socialización, los niños en estas edades sí tienen aptitudes que genéricamente se le atribuyen al femenino, como, por ejemplo, la dedicación en las manualidades y la perspicacia emocional que las adultas no ven en ellos en su afán por atribuir estas características a las niñas.

\section{RELACIONES CON RESPECTO AL OTRO U OTRA}

De acuerdo con estudios, en el ámbito de la psicología, el interés, por parte de niñas y niños, en el sexo de sus pares femeninos y masculinos, comienza en edades muy tempranas (Espinosa, 2007). Así, las interrelaciones con sus coetáneos se desenvuelven desde el área de juegos y ayudan a la construcción de las identidades de género que en el futuro se establecerán como redes de una sociedad.

\section{Niña respecto a niña:}

En los niveles de sala cuna, las niñas tienden a ignorarse, lo mismo ocurre en el nivel heterogéneo, pero en menor medida. La propensión de acercase a sus pares femeninas está 
promovida por el interés de conseguir algún tipo de beneficio, ya sea inmediato o a largo plazo. Casi en la totalidad, las niñas muestran un aire mezquino, queriendo llamar la atención de modo muy egocéntrico y agresivo.

En muchas ocasiones discutieron entre ellas, de diferentes niveles, por quién llamaba más mi atención, hasta el punto de impedirme siquiera mirar a los niños o cualquiera de sus compañeras. La poca solidaridad femenina se manifiesta en su posición individualista de conseguir los objetos de su interés, sólo como último recurso utilizaron la ayuda de sus pares femeninas.

\section{Niña respecto a niño:}

Las niñas con espíritu de liderazgo sienten la necesidad de ser parte del mundo de los hombres, sin embargo, también tienen aprensión de los asuntos públicos, pues las invade la vergüenza al ridículo; de esta manera opinan menos cuando el grupo está constituido por una mayoría masculina.

Cuando por fin logran tener el interés de los niños o participan como voz de mando sobre ellos, deciden ignorarlos dándose importancia, hasta que ellos pierden provecho y se alejan. Nuevamente ellas buscan ser vistas por el mundo masculino y se forma un círculo de acciones.

Respecto a sus pares masculinos de edades menores, el trato responde como si se tratara de bebés, algunas acuden al instinto maternal y los cuidan de golpes u objetos en el paso, otras ejercen su voz de mando y les ordenan cosas, y, por último, están aquellas que simplemente ignoran la existencia de los más pequeños.

La niña con respecto al niño sea de su edad o no, se comporta en un ir y venir de visibilización e invisibilización constante, este hecho ya sea porque se subordina a sí misma o porque los hombres la opacan. Ayuda, en buena parte, la interiorización inconsciente de los roles femeninos que incluyen ciertas características y excluyen otras.

\section{Niño respecto a niño:}

Como bien destaqué anteriormente, Kimmel (1997) rescata que la aprobación Homosocial es una constante búsqueda hacia la confirmación de masculinidad. Durante el período de observación, dos de los niños del Nivel Medio se consideraban amigos, en esta relación siempre hubo una necesidad por asegurar que ambos eran, efectivamente, amigos, de este modo solían preguntarse si lo que hacían era importante, llamativo o simplemente, si estaba bien. Si uno se subía sobre la mesa, siempre buscaba que su amigo lo imitara, como modo de aprobación o rechazo del comportamiento.

Con respecto a niño de Nivel Medio a niño del Sala Cuna, los primeros los ven como bebés fáciles de subordinar, y en la mayoría de los casos, ignorar. Muy a menudo los niños grandes se enfadaban cuando los más pequeños los imitaban, por lo que intentaban alejarse al máximo del grupo menor. Caso contrario, los niños de las Salas Cunas Mayor y Mixtas, éstos veían con 
admiración los quehaceres de los más grandes, queriendo siempre imitarlos y buscando su aprobación para legitimarse.

\section{Niño respecto a niña:}

En los grupos Sala Cuna Mayor y Nivel Medio, se observa que los niños conocen su poder, en términos de fuerza en el primer grupo; y en términos de manipulación de esa fuerza, en el segundo.

Incluyen a las mujeres en sus juegos de poder cuando requieren del cuerpo femenino para cumplir sus propósitos, las utilizan como un objeto y las ignoran cuando ya no las necesitan. Saben que con un chantaje o un comentario burlesco las reprimirá y así ellas dejarán de inmiscuirse en sus asuntos.

\section{REFLEXIONES}

Tanto las educadoras, como las asistentes y apoderadas entrevistadas carecían de una definición o caracterización del término, vagas alusiones fueron capaces de responder y describir a la hora de consultar acerca de los roles de género. Junto a aquello, la negación de prácticas sexistas tanto al interior del Jardín como dentro de los hogares fue tajante, todas dicen que el machismo existe y corresponde a una característica típica chilena, pero sólo son capaces de observarla fuera de sus realidades.

Se observó que tanto la femineidad como la masculinidad responden a constructos sociales y culturales que se forjan a través de la socialización con el mundo adulto, pero también mediante la propia creación de las y los preescolares, puesto que no siempre coincidió el imaginario femenino y masculino de las adultas, con los roles de género que desarrolla cada sexo en la práctica.

En el ejercicio del poder, tanto hombres como mujeres mantienen acciones de dominación y subordinación, ya sea para con sus sexos o con los opuestos. Sin embargo, se reconoce a la dominación masculina como una de las gestoras de violencia más influyente en las sociedades del mundo, por su constante invisibilización y supresión del femenino, y sus expresiones.

La naturalización de la dualidad de género viene dada desde la distinción anatómica de los cuerpos y justifica las diferencias sociales que se han establecido para los sexos, convirtiendo a la dominación de los hombres en arraigos conscientes e inconscientes del conjunto cultural. (Maldonado, 2003). Cuando se habla de violencia, se puede tratar de tres tipos. La primera, física y que corresponde a golpes de cualquier nivel, desde empujones hasta el uso de armas. La psicológica, que afecta a psique de quien ha sido víctima de violencia, puede tratarse de insultos hasta la alteración de la estabilidad emocional. Y, por último, la violencia simbólica. Este último tipo de violencia se encuentra muchas veces en el currículo oculto de distintos sistemas institucionales, como en cualquier tipo de agrupación; incluye la reproducción de hábitos de 
hombres y mujeres, en el cual ambos justifican el actuar de las injusticias que se cometen bajo estos símbolos.

En los niños y niñas suele estar oculto en los objetos materiales de juegos, actividades mal diseñadas, poco integrador, trato no igualitario y tantos otros. Al interior de la institución en la cual se desarrolló este estudio, la violencia simbólica se encontró principalmente en las actividades mal diseñadas durante el período estacional, en donde no se revisaba el tipo de películas a ver, ni la música a escuchar, o la falta de atención en los juegos de niños y niñas, reproductores de sexismos.

Finalmente, el ejercicio del poder como parte de la violencia simbólica provoca que, tanto víctimas como victimarios, no siempre logren darse cuenta de las prácticas sexistas que desarrollan o de las cuales son afectadas. Se demostró en este estudio mediante, el discurso oral acerca de las percepciones del género y discurso oculto del relato de las mujeres entrevistadas, que el poder de dominación existe en sus lugares de trabajo y vivienda.

Se espera que la visibilización de los asuntos de género traiga consigo un proceso de educación, el cual proporcione un espacio de debate dentro del sistema escolar, pero que se exteriorice en el mundo familiar de las y los párvulos, de este modo se contribuiría de un mejor modo en la aplicación de métodos y enseñanzas igualitarias para niños y niñas que traspasen la sólo visibilización terminológica LAS y LOS.

\section{BIBLIOGRAFÍA}

Bolin, A. (2003) La transversalidad de género: contexto cultural y prácticas de género. Antropología de la sexualidad y diversidad cultural. Talasa.

Bourdieu, P. (2000) La dominación masculina. Editorial Anagrama. Barcelona ISBN: 84-339.

Butler, J. (2006) Regulaciones de género. Revista de Estudios de Género. La Ventana, 7-36.

Espinosa, M. (2007) La Construcción del Género desde el Ámbito Educativo: Una Estrategia Preventiva. EMADUKE. Recuperado de http://www.emakunde.euskadi.net/contenidos/informacion/nahiko_materialak/eu_pon encia/adjuntos/ANGELES\%20ESPINOSA\%20La\%20construcci\%C3\%B3n\%20del\%20g\%C3\% A9nero\%20desde\%20el\%20\%C3\%A1mbito\%20educativo.pdf

Guzmán, L. (S/F) Roles Sexuales, Roles de Género y Poder. Programa Mujer y Derechos Humanos. Recuperado de http://www.ts.ucr.ac.cr/binarios/docente/pd-000124.pdf

JUNJI. (2005) Marco Curricular I. Departamento Técnico Junta Nacional de Jardines Infantiles. Chile. 
Kaufman, M. (1997) Las experiencias contradictorias del poder entre los hombres. Chile: ISIS.

Kimmel, M. (1997) Homofobia, temor, vergüenza y silencio en la identidad masculina. ISIS.

Lagarde, M. (1990). Identidad femenina. Secretaría Nacional de Equidad y Género.

Lamas, M. (2004). Diferencias de sexo, género y diferencia sexual. Cuicuilco. Revista de Ciencias Antropológicas, 95-118.

Maldonado Gómez, M. (2011) A propósito de La dominación masculina de Pierre Bourdieu. Sociedad y Economía 4, 69-74.

Rivero, J. (1998) La educación infantil en el siglo XXI. Proyecto principal de educación en América Latina y el Caribe. Boletín.

San Pelayo, E. (2008) Educación de la sexualidad preescolar: Un enfoque alternativo y participativo. Revista SUMMA Psicológica UST, 53-62.

Serret, E. (1990). La subjetividad femenina en la cultura occidental moderna. Sociológica México. 